\title{
Testing the decoy effect in the presence of store brands
}

\author{
Sellers, R. y Nicolau, J.L.
}

Universidad de Alicante

Puede citar este artículo:

Sellers, R. y Nicolau, J.L. (2015): “Testing the decoy effect in the presence of store brands”. International Journal of Retail and Distribution Management. Vol. 43, n 2, pp. 113-125. DOI: 10.1108/IJRDM-07-2013-0144 


\section{Testing the decoy effect in the presence of store brands}

\section{Structured abstract}

Purpose: In this paper, the decoy effect is tested in the framework of sales promotion, by conducting several experiments to figure out how this decoy effect is influenced by the presence or absence of a store brand.

Design/methodology/approach: Several experiments have been conducted to test the validity of the decoy effect and rule out some explanations for the changes in demand that take place. The experiments consider three brands (two national brands and one store brand). All the brand names and prices employed in the experiment are real.

Findings: The results indicate that, as expected, the inclusion of a decoy in the choice set significantly increases the consumer's relative preference for the promoted product; however, more importantly, the results also show that store brand consumers are more influenced by a decoy than national brand consumers.

Originality/Value: This article presents the first evidence of the decoy effect in the presence of store brands.

Keywords: Store Brands, Promotion, Decoy

Article Classification: Research Paper

\section{Introduction}

In recent years, store brands have gained big market shares in almost every country in Western Europe and are widely offered by European mass retailers (Fall et al., 2013). For example, these brands represent about $40 \%$ of the total purchases in grocery stores in Spain (Nielsen, 2012). The rapid expansion of store brands has generated a vast body of academic research (Burt y Davies, 2010; Hyman et al., 2010), and could be explained by the potential benefits they have for retailers. Among these benefits, Chen et al. (1999) highlight that store brands can be used to attract customers and make more marketing profits from these attracted customers as well as from loyal customers. Further, Sayman and Raju (2004) show that adding a store brand to the shelves of the retailer increases sales of existing store brands, as there is a positive externality across store brands that might be termed as "umbrella brand" 
effect. Their findings also provide evidence that the retailer may want to design its store brand strategy to take advantage of linkages among products. Furthermore, Sudhir and Talukdar (2004) show that consumers who buy more store brands in many categories are more profitable for the store than consumers who buy relatively more national brands. Thus, selling more store brands does not appear to increase consumers' price sensitivity or cause lower revenues or profits. Rather, it allows the store to differentiate itself relative to other stores, thereby raising profits. Further, they allow a wide range of product options to be offered to meet the differing needs and values of customer groups (Anselmsson and Johansson, 2007). Finally, Kremer and Viot (2012) show that store brands have a positive impact on the retailer image.

Store brands, which are created, supervised and sold exclusively by a retailer, compete in almost every product category with major national brands as well as international manufacturers' brands (Buck, 1997; Burt, 2000). Thus, an important strategic implication derived from the rapid growth of store brands is related to the relationship established with manufacturers, especially with manufacturers of national brands. A store brand can be a strategic tool used by retailers to generate greater market power in a category (Chintagunta et al., 2002; Bonfrer and Chintagunta, 2004), which could ultimately affect the relationship between retailers and manufacturers of national brands. In fact, Sayman and Raju (2004) find that offering more store brand products reduces the share of leading national brands, thus increasing the bargaining power of retailers against manufacturers (Narasimhan and Wilcox, 1998).

One of the strategies followed by manufacturers to counter the rise of store brands has been increasing promotions. Ailawadi et al. (2001) show that although there are two separate and sizeable customer segments that buy one but not the other, there is also a segment that usually buys store brands but buys manufacturer brands when they are promoted.

In this paper, the effect of a promotion run by a manufacturer in order to counter the rise of store brands has been analyzed. This effect has been analyzed conducting several experiments to figure out how this effect is influenced by the presence or absence of a store brand and the presence or absence of a decoy. The decoy effect (or asymmetric dominance effect) refers to the addition of a new alternative (a decoy) in the choice set that increases the choice for one of the existing alternatives that dominates the new one. This effect assumes that consumers tend to change their preference between two options (A and B) when presented with a third option (C) that is asymmetrically dominated by one of the initial 
options (A or B). An option is asymmetrically dominated when it is inferior in all respects to one option (say A); however, in comparison to the other option (say B), it is inferior in some respects and superior in others.

The contribution of the paper is that for the first time it is analyzed the effect of a promotion in the presence or absence of a store brand when an asymmetrically dominated alternative (a decoy) is also included in the choice set. An important issue in marketing is to understand how the introduction of a promotion into the market will be reflected in choice probabilities or market shares. In this sense, if the promotion is held in the presence of a decoy which is dominated by the promotion but not by another alternative in the choice set, adding such an alternative can increase the probability of choosing the promoted item that dominates it. Further, and also for the first time in the store brand literature, this effect is analyzed in the presence or absence of a store brand in the choice set.

In order to fulfill this objective, the remainder of the paper is arranged as follows. The second section reviews previous literature on store brands and the decoy effect. The third section presents the experiments conducted to test the decoy effect along with their results. Finally, the fourth section summarizes the main conclusions of the paper.

\section{Literature review: Store brands and the decoy effect.}

Since the appearance of store brands, retailers have gone from conceiving it as a tool for increasing market share and profitability, to seeing that there are important benefits derived from the correct management of these brands (Oubiña et al., 2006). Store brands have been implemented in clear competition to manufacturer brands, and the rise of store brands has been responded to by manufacturers in a number of different ways (Ailawadi and Keller, 2004), in an effort to mitigate their impact. Among these strategies, manufacturers have tried decreasing costs and cutting prices, increasing promotions, increasing $R \& D$ expenditures, introducing discount "fighter” brands, or even supplying private label makers. Regarding promotions, Ailawadi et al. (2001) show that there are three customer segments: two separate and sizeable segments that buy one but not the other and a third segment of value conscious consumers who usually buy store brands but buy manufacturer brands when they are promoted. The existence of these different segments implies that manufacturers and retailers have the opportunity to either avoid each other or to compete head-to-head. If manufacturers target the deal-focused segment and retailers target the store-brand focused segment the tug of 
war between manufacturers and retailers should diminish. However, if manufacturers and retailers both target the use-all segment, it can exacerbate competition within the channel.

Ailawadi et al. (2001) show that manufacturers could partially combat the store brand threat through promotions. They can do so with price and convenience oriented messages and in-store displays designed to encourage impulsive purchases. In fact, several studies show that store brand consumers are more prone to price changes than national brand consumers (Richardson et al., 1996), so it is expected that there is also a segment of store brand users that is more sensitive to promotions than national brand consumers. Several authors (e.g. Steiner, 1994; Blattberg and Wisniewski, 1989) have found that price effects are asymmetric as manufacturer's price cuts hurt store brands more than store brand price cuts hurt the national brands.

The widespread use of sales promotions has led to a considerable debate over their effectiveness (Kwok and Uncles, 2005). Sales promotions and product enhancements are commonly expected to increase a brand's sales when they do not negatively impact its utility and cost (Simonson et al., 1994). Some researchers have shown that sales promotions lead to real long-run increases in sales and profits (Dhar and Hoch, 1996). However, critics argue that sales promotions are ineffective as they make consumers more promotion prone, resulting in market share losses in the long run (Ehrenberg et al., 1994). In fact, many marketers and academics often view the reliance on sales promotions, especially monetary promotions, as a suboptimal consequence of price competition caused by myopic management (Buzzell et al, 1990). This discrepancy suggests there are other factors at work. Marketers can employ several methods to enhance the attractiveness of their offerings, such as adding unique product features or offering a free premium. Chandon et al. (2000) state that sales promotions are more effective when they provide benefits that are congruent with those of the promoted product, while Shampanier et al. (2007) show that people overreact to free products.

The short and long term effects of these tactics on brand evaluations and sales have been studied extensively by marketing researchers and are often discussed in the marketing literature (e.g., Blattberg and Neslin, 1990). Generally speaking, it is assumed that enhancing a product with features that do not negatively affect other attributes can only help short term sales. That is, the purchase probability of consumers who find the promotion attractive will increase, whereas the purchase likelihood of other consumers will not be affected. 
An interesting issue is to understand the way the introduction of a promotion into a market is reflected in choice probabilities. A standard model used in such situations is to assume that a new offering (the promoted item) will take consumers from others in proportion to their original shares. This assumption of proportionality is first incorporated in the Luce (1959) model of choice. Several authors show that this assumption of proportionality fails in some situations. In this sense, the similarity hypothesis (Tversky, 1972) states that a new offering takes disproportionately more share from those similar to it than from dissimilar items. The underlying regularity assumption in these models states that the addition of a new alternative cannot increase the probability of choosing a member of the original set.

However, in their seminal paper, Huber, Payne, and Puto (1982) evidence that the similarity hypothesis and the regularity condition can be consistently violated by the addition of an asymmetrically dominated alternative. The relative preference of a target product over a competitor can be increased by providing a third alternative (a decoy) that is clearly inferior to the target but is not necessarily inferior to the competitor. The decoy effect (or asymmetric dominance effect) in marketing is the phenomenon whereby consumers tend to have a specific change in preference between two options when presented with a third option that is asymmetrically dominated. An option is asymmetrically dominated when it is inferior in all respects to one option; but, in comparison to the other option, it is inferior in some respects and superior in others. In other words, in terms of specific attributes that determine preferability, it is completely dominated by (i.e., inferior to) one option and only partially dominated by the other. When the asymmetrically dominated option is present, a higher percentage of consumers will prefer the dominating option than when the asymmetrically dominated option is absent. The asymmetrically dominated option is therefore a decoy serving to increase preference for the dominating option.

This decoy effect, first identified by Huber et al. (1982), has been replicated in a wide variety of choice situations involving both commercial products (for example, Ariely and Wallsten, 1995; Dhar and Simonson, 2003; Heath and Chatterjee, 1995; Pettibone and Wedell, 2000) as well as non-commercial products such as political candidates (Pan, O'Cuny, and Pitts, 1995) or jobs (Highhouse, 1996).

Decoy effects appear to be robust as they can be found in a variety of product classes ranging from restaurants to light bulbs and occur regardless of whether choice sets are manipulated between subjects (Heath and Chatterjee, 1995). Further, decoy effects are important for both theory and practice as they involve various perceptual and decision making 
processes. In this paper, the decoy effect is analyzed in the framework of sales promotion. In fact, when a promotion is undertaken, the introduction of a decoy into the choice set could result in a higher number of consumers shifting their choice to the promoted targeted product increasing the effectiveness of the promotion. The decoy is the original product without the promotion, which is now asymmetrically dominated by the promoted item.

There are several factors that could moderate this effect. Specifically, Heath and Chatterjee (1995) show an effect of brand quality. In this sense, from their analysis it is concluded that decoys reduce shares of lower-quality competitors more than they reduce shares of higher-quality competitors. Another factor that could affect the decoy effect is examined by Kim et al. (2006), who investigate the role of brand names in the effect of a decoy on preference construction. In their analysis, the averaging view and category-based processing view are considered to make predictions. In fact, their results predict a general reduction in the decoy effect if the real brand names are provided along with attribute information about choice alternatives (Kim et al., 2006). On the other hand, the two views make different predictions regarding the moderating role of consumer brand knowledge. That is, the category-based processing view predicts a significant moderating role of brand knowledge (i.e., a significant reduction of decoy effects by presenting real brand names only for high brand knowledge conditions), but the averaging view predicts no such role. Bronnenberg and Wathieu (1996) study whether national brands may easily attract consumers from store brands through promotions, whereas store brands are relatively ineffective in attracting consumers from national brands through such means. Their results show that, given any two brands, there is an asymmetric promotion effect in favor of the higher quality/higher price brand if, and only if, the quality gap between the brands is sufficiently large in comparison with the price gap. This result explains why store brand customers overreact to promotions compared to national brand consumers.

\section{Testing the phenomenon.}

An online experiment has been conducted to test the validity of the decoy effect and rule out some explanations for the changes in demand that take place when a promotion is held in the presence or absence of a store brand.

Participants were asked to suppose they were going to buy one grocery product (one liter of chicken broth). All the brand names (two national brands and one store brand) and prices employed in the experiment are real. Thus, the following alternatives were considered: 
One liter of Knorr broth (Unilever), hereafter product K, one liter of a promoted pack of Knorr broth, hereafter, product KP, one liter of Gallina Blanca broth (the Spanish market leader brand, which belongs to the Agrolimen Group), hereafter, product G, and one liter of Carrefour broth (Spanish leader in the hypermarket segment), hereafter called product $\mathrm{S}$ and which represents the store brand. As the effect of a promotion is analyzed, note that in this case the regular pack of Knorr broth (product K) is the decoy, as it is dominated by the promoted pack of Knorr broth (product KP). Actually, they both have the same price and brand, but the promoted pack contains $10 \%$ extra free. This promotion is employed as it is expected to be effective and easily understood by consumers. Shampanier et al. (2007) show that when people have a choice set with two products, one being free (in this case, an extra $10 \%$ free), they favor the free product as if a zero price not only conveys the idea of no-cost but implicitly has extra value.

The participants were randomly assigned into the three specific experiments conducted. After some adjustments to discard incomplete responses, the final sample is comprised of 920 participants (294 in the first experiment, 308 in the second experiment and 318 in the third experiment). Participants were asked to make a hypothetical choice among two, three or four alternatives, with each alternative defined by the product (brand) and its price (see Table 1). Each experiment involves three conditions which provides a simple decision environment and a straightforward test of the effects. The percentage of times the target is chosen (which could be a proxy of the market share) with and without the decoy present is compared to test the effect of the promotion in the presence or absence of a decoy.

$<$ Take in Table $1>$

\subsection{Experiment 1}

Description. 294 buyers are asked to make a hypothetical choice between a Gallina Blanca broth (product G), a promoted Knorr broth (target product KP), and a regular Knorr broth (decoy product K). The three conditions in Experiment 1 are as follows (Table 1): i) the first is the neutral condition in which individuals choose one of the following two alternatives: product $\mathrm{K}$ or product $\mathrm{G}$. The alternative of not buying is not considered; ii) the second condition implies choosing between the target (product KP) and product G. The purpose of Condition 2 is to estimate the effect of the promotion in the absence of a decoy; and iii) the third condition is the decoy condition, in which the target (product KP) and the competitor (product G) are offered jointly with the decoy (product K). 
Results. As can be seen in Table 2 and Figure 1, under Condition 1, the demand for product $\mathrm{G}(61.2 \%)$ is significantly higher than that of product $\mathrm{K}(38.8 \%),(\mathrm{t}(294)=3.94, p<0.001)$. This mere descriptive result indicates that product $\mathrm{G}$ is generally preferred to product $\mathrm{K}$, which is consistent with the real market share. Note, however, that the result to be analyzed is how these percentages vary when transitioning from Condition 1 to Condition 2, that is, when product $\mathrm{K}$ is replaced by the promoted product KP. It is observed that the demand for promoted product KP broth increases significantly from $38.8 \%$ to $51 \%(\mathrm{t}(441)=2.43, p<0.05)$ and the demand for product $\mathrm{G}$ falls significantly from $61.2 \%$ to $49 \%(\mathrm{t}(441)=2.43, p<0.05)$. This result confirms the effectiveness of the promotion to increase product sales. In the end, consumers do not forsake the possibility of obtaining $10 \%$ extra product, and therefore they change their preferred alternative.

$<$ Take in Figure 1>

As for Condition 3, in which the decoy (product $\mathrm{K}$ ) is also presented, the demand for promoted product KP increases from $38.8 \%$ to $57.8 \%(\mathrm{t}(441)=3.82, p<0.001)$, while the demand for competitor product $\mathrm{G}$ decreases significantly from $61.2 \%$ to $42.2 \%(\mathrm{t}(441)=3.82$, $p<0.001)$. Further the demand for promoted product KP increases from 51\% to $57.8 \%$ $(\mathrm{t}(294)=1.17 ; p=0.24)$ when transitioning from Condition 2 to Condition 3 . This result confirms that adding an asymmetrically dominated alternative violates the regularity condition, as people would change their preference between two options when this new third asymmetrically dominated option is introduced, in such a way that the dominating alternative (promoted product KP) raises its demand (Huber et al., 1982). In fact, the demand for target product KP is higher when the decoy is present (57.8\%) than in the absence of the decoy (51\%).

\subsection{Experiment 2.}

Description. This experiment is exactly the same as Experiment 1 except for the competitor. In this case product $\mathrm{G}$ is replaced by the store brand alternative (product $\mathrm{S}$ ). 318 buyers are asked to make a hypothetical choice between the alternatives in the choice set. This experiment analyzes the decoy effect in the presence of a store brand. The three conditions in Experiment 1 are as follows (Table 1): i) the first is the neutral condition in which individuals choose between product S (store brand) and product $\mathrm{K}$ (national brand); ii) the second condition implies choosing between the target (promoted product KP) and product S; and iii) 
the third condition is the decoy condition, in which the target (promoted product KP) and the store brand (product S) are offered jointly with the decoy (product K).

Results. As can be seen in Table 2 and Figure 2, under Condition 1, the demand for product S is significantly higher than that of the product $\mathrm{K}, 60.1 \%>39.9 \%,(\mathrm{t}(318)=3.67, p<0.001)$, indicating that the store brand product is generally preferred to the national brand product. When transitioning from Condition 1 to Condition 2 the results vary. That is, when product $\mathrm{K}$ is replaced by promoted product KP, it is observed that the demand for product KP increases significantly from $39.9 \%$ to $56 \%(\mathrm{t}(477)=3.35, p<0.001)$ and the demand for product $\mathrm{S}$ is dramatically reduced from $60.1 \%$ to $44 \%(\mathrm{t}(477)=3.35, p<0.001)$. This result again confirms that the promotion is an effective tool to increase product sales, as consumers do not forsake the possibility of obtaining $10 \%$ more product, and thus they change their preferred alternative.

$<$ Take in Figure 2>

As for Condition 3, in which the decoy (product K) is also presented, the demand for the target promoted product KP increases again from $39.9 \%$ to $70.4 \%(\mathrm{t}(477)=6.71, p<0.001)$, while the demand for the competitor product $\mathrm{S}$ decreases from $60.1 \%$ to $29.6 \%(\mathrm{t}(477)=6.71$, $p<0.001$ ). Further the demand for promoted product KP increases from $56 \%$ to $70.4 \%$ $(\mathrm{t}(318)=2.69 ; p<0.01)$ when transitioning form Conditions 2 to Condition 3. This result confirms the decoy effect in the presence of a store brand.

The most interesting result from Experiment 2 compared to Experiment 1 is the proportional decrease of the market share of product $S$ in Experiment 2 against the proportional decrease of the market share of product $G$ in Experiment 1. In Experiment 1, the demand for product $\mathrm{G}$ decreases from $61.2 \%$ to $42.2 \%$, implying a $31.0 \%$ proportional decrease in the presence of the decoy (Condition 3). In Experiment 2, the demand for product S decreases from $60.1 \%$ to $29.6 \%$, implying a $50.7 \%$ proportional decrease in the presence of the decoy (Condition 3). Thus, the proportional increase in the demand for the target promoted product KP is higher in Experiment 2 than in Experiment 1. In the presence of the store brand the market share of the target product increases from $39.9 \%$ to $70.4 \%$, implying 30.5 points more market share. However, in Experiment 1, when the target product is competing against another national brand, demand increases from 38.8\% to 57.8\%, implying 20 points more market share. Interestingly, this result suggests that the decoy effect is higher in the presence of a store brand. 


\subsection{Experiment 3.}

Description. This experiment is the most realistic of the 3 and is a combination of the previous two. It analyzes the decoy effect in the presence of two competitors: a store brand and a national brand. In this case, 308 buyers are asked to make a hypothetical choice between the alternatives in the choice set. The three conditions in Experiment 3 are as follows (Table 1): i) the first is the neutral condition in which individuals choose between the store band (product S), the national brand (product G) and the national brand (product K); ii) the second condition implies choosing between the target (promoted product KP), the store brand (product S) and the national brand (product G); and iii) the third condition is the decoy condition, in which the target (promoted product KP), the store brand (product S) and the national brand (product G) are offered jointly with the decoy (product K).

Results. As can be seen in Table 2 and Figure 3, under Condition 1, the demand for product $\mathrm{G}$ is $50.6 \%$, higher than that of the product $\mathrm{K}(12.7 \%<50.6 \%(\mathrm{t}(308)=19.6, p<0.001))$ and product $S(36.7 \%<50.6 \%(\mathrm{t}(308)=4.84, p<0.001))$. When transitioning from Condition 1 to Condition 2 the results vary. That is, when product $\mathrm{K}$ is replaced by promoted product KP, the demand for product KP increases significantly from $12.7 \%$ to $29.2 \%(\mathrm{t}(462)=3.99, p<0.001)$. Simultaneously, the demand for product S is reduced from $36.7 \%$ to $29.9 \%$ and the demand for product $\mathrm{G}$ is reduced from $50.6 \%$ to $40.9 \%$. This result again confirms that the promotion is an effective tool to increase sales of the product. The increase in the demand of product KP $(16.5=29.2-12.7)$ comes both from product $\mathrm{S}(6.8 \%)$ and from product $\mathrm{G}(9.7 \%)$.

$<$ Take in Figure 3>

As for Condition 3, in which the decoy (product K) is also presented, demand for the target promoted product KP increases drastically from $12.7 \%$ to $54.5 \%$ (t(462) $=9.41$, $p<0.001$ ), while demand for competitor product $\mathrm{G}$ decreases from $50.6 \%$ to $29.9 \%$ $(\mathrm{t}(462)=4.44, p<0.001)$ and demand for product $\mathrm{S}$ decreases from $36.7 \%$ to $15.6 \%$ $(\mathrm{t}(462)=4.34, p<0.001)$. Further the demand for promoted product KP increases from $29.2 \%$ to $54.5 \%(\mathrm{t}(308)=4.65 ; p<0.001)$ when transitioning from Condition 2 to Condition 3. This result again confirms the presence of a decoy effect, as adding an asymmetrically dominated alternative raises demand for the dominating alternative (promoted product KP). As in Condition 2, the increase in demand for promoted product KP (41.8=54.5-12.7) comes both from store brand consumers (21.1) and from product G (20.7). A more interesting result is that the proportional decrease in demand for product $S$ (store brand) is higher (57.5\%) than 
the proportional decrease of demand for product G (national brand) (41\%), which shows that store brand buyers are more influenced than national brand buyers by promotions when a decoy is also included in the choice set.

$<$ Take in Table 2>

\section{Conclusions.}

The rise of store brands is a challenge for national brand managers. Face-to-face competition on retail shelves adds complexity to the decision process; nevertheless, this challenge also allows managers to use the interrelationships among the decisions to maximize sales and promotions. This article analyzes the decoy effect when a promotion is established in the presence or absence of a store brand in the choice set. Stemming from Huber et al's. (1982) model, we adapt and apply it to a three-component context, and carry out three experiments. As several studies have shown that promotions of national brands yield more effect than those of store brands (e.g., Blattberg and Wisniewski, 1989) the participants are asked to make a hypothetical choice between three products: one store brand and two national brands.

Experiments 1 and 2 show evidences of the decoy effect when the competitor is a national brand and a store brand, respectively. The results suggest that store brand consumers are more influenced by promotions than national brand consumers. Further, the decoy effect is higher in the presence of a store brand competitor than for a national brand competitor. The alternatives in Experiment 3 represent the real alternatives consumers have when choosing a product, having the possibility of buying the store brand or one of two national brands. This inclusion affords realism to the experiment because it introduces brand commitment when analyzing the asymmetric dominance effect. The results suggest that store brand consumers are more likely to change their selection in order to benefit from a promotion than national brand consumers. This result is consistent with and corroborates the results of previous experiments.

The results of this article show that the decoy effect is not only confined to national brands (as several authors show) but also applies to store brands, even with a multi-alternative context. Further, the results have important managerial implications, mainly in the realm of sales promotion policies. Although many marketers and academics often view the reliance on sales promotions, especially monetary promotions, as a suboptimal consequence of price competition caused by myopic management (Buzzell et al, 1990), this paper shows that, in the short run, they are a reliable method of attracting store brand consumers to national brands. 
The existence of multiple types of consumer benefits provides a stepping stone for a benefit congruency framework, which argues that a sales promotion's effectiveness is determined by the congruency between its benefits and those of the promoted product (Chandon et al., 2000). Further, if a decoy is included when the promotion is held, the effectiveness of the promotion is even higher.

Finally, the following important avenues for further research are highlighted: i) applications to other product categories would shed light onto common (or different) reactions between brands; ii) in the experimental research, a three-component context has been considered, including one store brand and two national brands. In this case the store brand is the cheapest alternative, and store brand consumers appear to be the most influenced by a promotion. Nowadays, retailers offer several store brands for the same product category in order to segment the market. Thus, more research is needed to analyze this effect.

\section{References.}

Ailawadi, K.L. and Keller, K.L. (2004), “Understanding retail branding: conceptual insights and research priorities”, Journal of Retailing, Vol. 80 No. 4, pp. 331-342

Ailawadi, K.L., Neslin, S.A. and Gedenk, K. (2001), "Pursuing the value conscious consumer: store brands versus national brand promotions”, Journal of Marketing, Vol. 65 No. 1, pp. 71-89.

Anselmsson, J. and Johansson, U. (2007), “Corporate social responsibility and the positioning of grocery brands”, International Journal of Retail \& Distribution Management, Vol. 35 No. 10, pp. 835-56.

Ariely, D. and Wallsten, T. (1995), "Seeking subjective dominance in multidimensional space: An explanation of the symmetric dominance effect”, Organizational Behavior and Human Decision Processes, Vol. 63, pp. 223-232.

Blattberg, R.C. and Neslin, S.A. (1990), Sales promotion: Concepts, methods, and strategies. Prentice-Hall: Englewood Cliffs, NJ.

Bonfrer, A. and Chintagunta, P.K. (2004), "Store brands: Who buys them and what happens to retail prices when they are introduced?”, Review of Industrial Organization, Vol. 24 No. 2, pp. 195-218.

Bronnenberg, B.J. and Wathieu, L. (1996), “Asymmetric promotion effects and brand positioning”, Marketing Science, Vol. 15, pp. 379-394. 
Buck, S. (1997), “The continuing grocery revolution”, Journal of Brand Management, Vol. 4 No. 4, pp. 227-238.

Burt, S. (2000), “The strategic role of retail brands in British grocery retailing”, European Journal of Marketing, Vol. 34 No. 8, pp. 875-90.

Burt, S. and Davies, K. (2010), "From the retail brand to the retailer as a brand: themes and issues in retail branding research”, International Journal of Retail \& Distribution Management, Vol. 38 No.11/12, pp. 865 - 878.

Buzzell, R., Quelch, J. and Salmon, W. (1990), “The costly bargain of trade promotion”, Harvard Business Review, Vol. 68 No. 2, pp. 141-49.

Chandon, P., Wansink, B. and Laurent, G, (2000), “A benefit congruency framework of sales promotion effectiveness”, Journal of Marketing, Vol. 64 No. 4, pp. 65-81

Chen, Y., Hess, J.D., Wilcox, R.T. and Zhang, Z.J. (1999), “Accounting profits versus marketing profits: a relevant metric for category management”, Marketing Science, Vol. 8 No. 3, pp. 208-229.

Chintagunta, P.K., Bonfrer, A. and Song, I. (2002), "Investigating the effects of store brand introduction”, Management Science, Vol. 48 (10), pp. 1242-1268.

Dhar, S.K. and Hoch, S.J. (1996), "Price discrimination using in-store merchandising”, Journal of Marketing, Vol. 60 No. 1, pp. 17-30.

Dhar, R. and Simonson, I. (2003), “The effect of forced choice on choice”, Journal of Marketing Research, Vol. 40, pp. 146-160.

Ehrenberg, A.S.C., Hammond, K. and Goodhardt, G.J. (1994) "The after-effects of price-related consumer promotions”, Journal of Advertising Research, Vol 34 No. 4, pp. 1121.

Fall, M., Chandon, J.L., Cliquet, G. and Philippe, J. (2013), "Factors influencing consumer behaviour towards store brands: evidence from the French market”, International Journal of Retail \& Distribution Management, Vol. 41 No. 6, pp. 422-441.

Heath, T.B. and Chatterjee, S. (1995), “Asymmetric decoy effects on lower-quality versus higher-quality brands: meta-analytic and experimental evidence”, Journal of Consumer Research, Vol. 22 No. 3, pp. 268-284. 
Highhouse, S. (1996) “Context-dependent selection: The effects of decoy and phantom job candidates,” Organizational Behavior and Human Decision Processes, Vol. 65 No. 1, pp. 68-76.

Huber, J., Payne, J.W. and Puto, C. (1982), “Adding asymmetrically dominated alternatives: Violations of regularity and the similarity hypothesis”, Journal of Consumer Research, Vol. 9, pp. 90-98.

Hyman, M.R., Kopf, D.A. and Lee, D. (2010), “Review of literature - future research suggestions: Private label brands: benefits, success factors and future research”, Journal of Brand Management, Vol. 17 No. 5, pp. 368-389.

Kim, J., Park, J. and Ryu, G. (2006), "Decoy effects and brands”, Advances in Consumer Research, Vol. 33, pp. 683-687.

Kremer, F. and Viot, C. (2012), "How store brands build retailer brand image", International Journal of Retail \& Distribution Management, Vol. 40 No. 7, pp. 528 - 543.

Kwok, S. and Uncles, M. (2005) "Sales promotion effectiveness: the impact of consumer differences at an ethnic-group level”. Journal of Product \& Brand Management, Vol. 14 No. 3, pp. 170-186.

Luce, R.D. (1959) Individual Choice Behavior. New York: John Wiley \& Sons, lnc.

Narasimhan, C. and Wilcox, R.T. (1998), "Store brands and the channel relationship: a cross-category analysis”, Journal of Business, Vol. 71 No. 4, pp. 573-600.

Nielsen (2012), Anuario 2012: La guía de los mercados de gran consumo, Nielsen, Madrid, Spain.

Oubiña, J., Rubio, N. and Yagüe, M.J. (2006), “Strategic management of store brands: an analysis from the manufacturer's perspective", International Journal of Retail \& Distribution Management, Vol. 34 No. 10, pp. 742-60.

Pan, Y., O’Curry, S. and Pitts, R. (1995), “The attraction effect and political choice in two elections”, Journal of Consumer Psychology, Vol. 4, pp. 85-101.

Pettibone, J. and Wedell, D. (2000) “Examining models of nondominated decoy effects across judgment and choice,” Organizational Behavior and Human Decision Processes, Vol. 81 No. 2, pp. 300-328. 
Richardson, P.S., Jain, A.K. and Dick, A.S. (1996), "Household store brand proneness: A framework”, Journal of Retailing, Vol. 72 No. 2, pp. 159-185.

Sayman, S. and Raju, J.S. (2004), "Investigating the cross-category effects of store brands”, Review of Industrial Organization, Vol. 24 No. 2, pp. 129-141

Shampanier, K., Mazar, N. and Ariely, D. (2007), “Zero as a special price: The true value of free products”, Marketing Science, Vol. 26 (6), pp. 742-757.

Simonson, I., Carmon, Z. and O'Curry, S. (1994), "Experimental evidence on the negative effect of product features and sales promotions on brand choice”, Marketing Science, Vol. 13 No. 1, pp. 23-40.

Steiner, R.L. (2004) "The nature and benefits of national brand/private label competition”, Review of Industrial Organization, Vol. 24 No. 2, pp. 105-127.

Sudhir, K. and Talukdar, D. (2004), "Does store brand patronage improve store patronage?”, Review of Industrial Organization, Vol. 24 No. 2, pp. 143-160.

Tversky, Amos (1972), "Elimination by Aspects: A Theory of Choice," Psychological Review, Vol. 79 No. 4, pp. 281-99.

Yuxin, C., Hess, J.D., Wilcox, R.T. and Zhang, Z.J. (1999), “Accounting profits versus marketing profits: a relevant metric for category management”, Marketing Science, Vol. 18 No. 3, pp. 208-229. 
Figure 1. Results of Experiment 1.

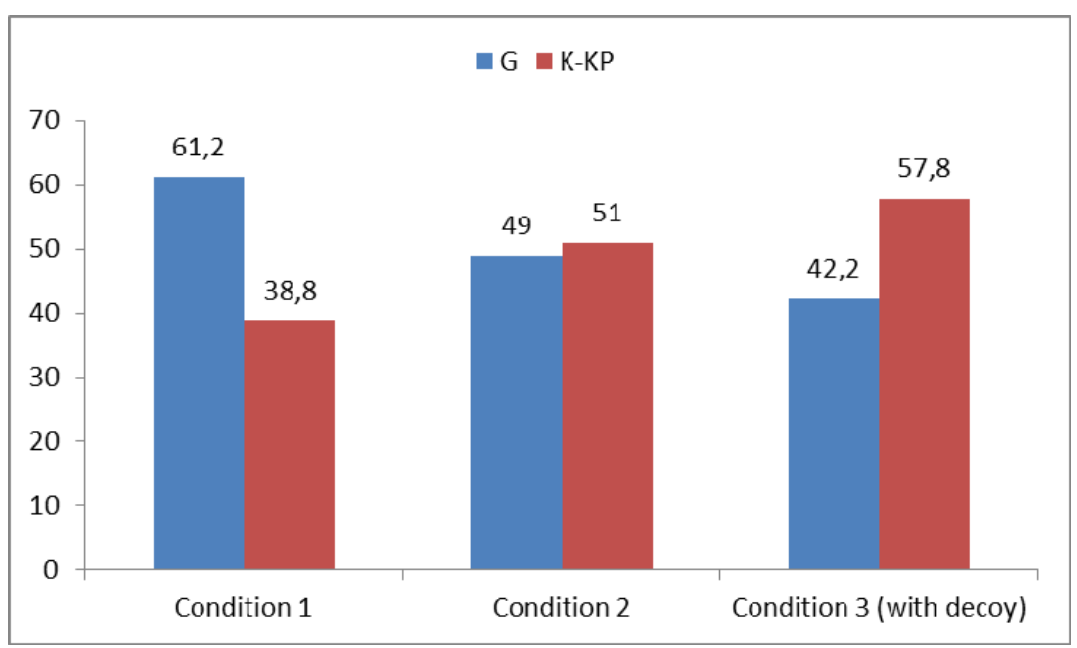

Figure 2. Results of Experiment 2.

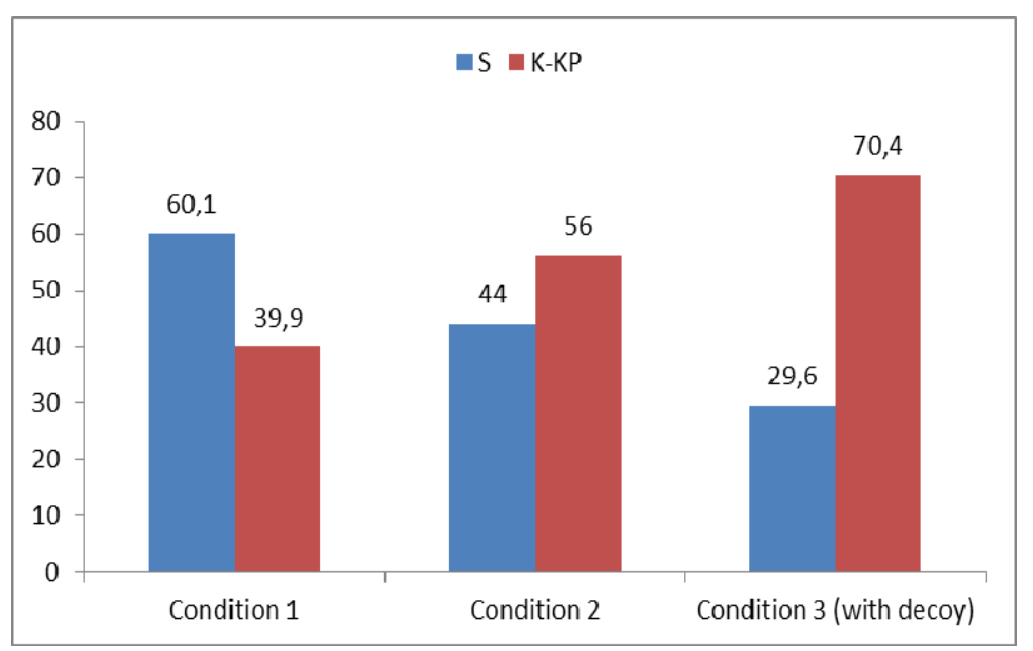

Figure 3. Results of Experiment 3.

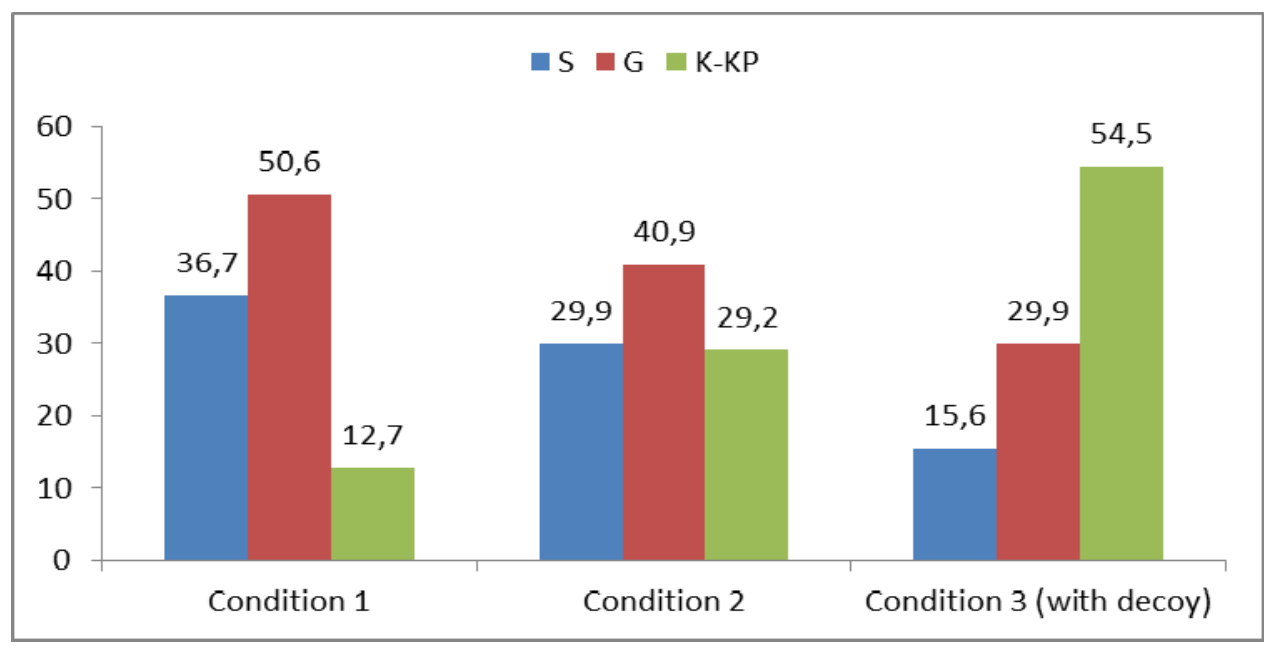


Table 1. Conditions in the experiments.

\begin{tabular}{|c|c|c|c|c|}
\hline & $\begin{array}{c}\text { Product S } \\
\text { (Carrefour) } \\
\text { (Store Brand } \\
\text { Competitor) } \\
\end{array}$ & $\begin{array}{c}\text { Product G } \\
\text { (Gallina Blanca) } \\
\text { (National Brand } \\
\text { Competitor) } \\
\end{array}$ & $\begin{array}{c}\text { Product K } \\
\text { (Knorr) } \\
\text { (Decoy) }\end{array}$ & $\begin{array}{c}\text { Product KP } \\
\text { (Promoted } \\
\text { Knorr) } \\
\text { (Target) } \\
\end{array}$ \\
\hline \multicolumn{5}{|c|}{ Experiment 1} \\
\hline Condition 1 & - & Price $1.55 €$ & Price $1.65 €$ & - \\
\hline Condition 2 & - & Price $1.55 €$ & - & $\begin{array}{c}\text { Price } 1.65 \\
+10 \% \text { Extra Free }\end{array}$ \\
\hline Condition 3 & - & Price $1.55 €$ & $\begin{array}{l}\text { Price } 1.65 € \\
\text { (Decoy) }\end{array}$ & $\begin{array}{c}\text { Price } 1.65 \\
+10 \% \text { Extra Free }\end{array}$ \\
\hline \multicolumn{5}{|c|}{ Experiment 2} \\
\hline Condition 1 & Price $1.15 €$ & - & Price $1.65 €$ & - \\
\hline Condition 2 & Price $1.15 €$ & - & - & $\begin{array}{c}\text { Price } 1.65 \\
+10 \% \text { Extra Free }\end{array}$ \\
\hline Condition 3 & Price $1.15 €$ & - & $\begin{array}{c}\text { Price } 1.65 € \\
\text { (Decoy) }\end{array}$ & $\begin{array}{c}\text { Price } 1.65 \\
+10 \% \text { Extra Free } \\
\end{array}$ \\
\hline \multicolumn{5}{|c|}{ Experiment 3} \\
\hline Condition 1 & Price $1.15 €$ & Price $1.55 €$ & Price $1.65 €$ & - \\
\hline Condition 2 & Price $1.15 €$ & Price $1.55 €$ & - & $\begin{array}{c}\text { Price } 1.65 \\
+10 \% \text { Extra Free }\end{array}$ \\
\hline Condition 3 & Price $1.15 €$ & Price $1.55 €$ & $\begin{array}{l}\text { Price } 1.65 € \\
\text { (Decoy) }\end{array}$ & $\begin{array}{c}\text { Price } 1.65 \\
+10 \% \text { Extra Free }\end{array}$ \\
\hline
\end{tabular}


Table 2. Summary of the results in the experiments.

\begin{tabular}{|c|c|c|c|c|}
\hline & $\begin{array}{c}\text { Product S } \\
\text { (Carrefour) } \\
\text { (Store Brand } \\
\text { Competitor) } \\
\end{array}$ & $\begin{array}{c}\text { Product G } \\
\text { (Gallina Blanca) } \\
\text { (National Brand } \\
\text { Competitor) } \\
\end{array}$ & $\begin{array}{c}\text { Product K } \\
\text { (Knorr) } \\
\text { (Decoy) }\end{array}$ & $\begin{array}{c}\text { Product KP } \\
\text { (Promoted } \\
\text { Knorr) } \\
\text { (Target) } \\
\end{array}$ \\
\hline \multicolumn{5}{|c|}{ Experiment 1} \\
\hline Condition 1 & - & 61.2 & 31.8 & - \\
\hline Condition 2 & - & 49 & - & 51 \\
\hline Condition 3 & - & 42.2 & 0 & 57.8 \\
\hline \multicolumn{5}{|c|}{ Experiment 2} \\
\hline Condition 1 & 60.1 & - & 39.9 & - \\
\hline Condition 2 & 44 & - & - & 56 \\
\hline Condition 3 & 29.6 & - & 0 & 70.4 \\
\hline \multicolumn{5}{|c|}{ Experiment 3} \\
\hline Condition 1 & 36.7 & 50.6 & 12.7 & - \\
\hline Condition 2 & 29.9 & 40.9 & - & 29.2 \\
\hline Condition 3 & 15.6 & 29.9 & 0 & 54.5 \\
\hline
\end{tabular}

